Research Report

\title{
Effects of $N$-acetylcysteine amide (NACA), a novel thiol antioxidant against glutamate-induced cytotoxicity in neuronal cell line PC12
}

\author{
Suman Penugonda ${ }^{\mathrm{a}}$, Suneetha Mare ${ }^{\mathrm{a}}$, Glenn Goldstein ${ }^{\mathrm{b}}$, William A. Banks ${ }^{\mathrm{c}}$, Nuran Ercal ${ }^{\mathrm{a}, *}$ \\ ${ }^{a}$ Department of Chemistry, University of Missouri-Rolla, 1870 Miner Circle, 142 Schrenk Hall, Rolla, MO 65409, USA \\ ${ }^{\mathrm{b}}$ Department of Surgery, New York University, New York, NY 10010, USA \\ ${ }^{\mathrm{c}}$ Geriatric Research Education and Clinical Center (GRECC), VA Medical Center, St. Louis, MO 63106, USA
}

Accepted 13 July 2005

Available online 24 August 2005

\begin{abstract}
Oxidative stress plays an important role in neuronal cell death associated with many different neurodegenerative conditions such as cerebral ischemia and Parkinson's disease. Elevated levels of glutamate are thought to be responsible for CNS disorders through various mechanisms causing oxidative stress induced by a nonreceptor-mediated oxidative pathway which blocks cystine uptake and results in depletion of intracellular glutathione (GSH). The newly designed amide form of $N$-acetylcysteine (NAC), $N$-acetylcysteine amide (NACA), was assessed for its ability to protect PC12 cells against oxidative toxicity induced by glutamate. NACA was shown to protect PC12 cells from glutamate (Glu) toxicity, as evaluated by LDH and MTS assays. NACA prevented glutamate-induced intracellular GSH loss. In addition, NACA restored GSH synthesis in a Glu $(10 \mathrm{mM})$ plus buthionine-sulfoximine (BSO) $(0.2 \mathrm{mM})$-treated group, indicating that the intracellular GSH increase is independent of $\gamma$-GSC ( $\gamma$-glutamylcysteinyl synthetase). The increase in levels of reactive oxygen species (ROS) induced by glutamate was significantly decreased by NACA. Measurement of malondialdehyde (MDA) showed that NACA reduced glutamate-induced elevations in levels of lipid peroxidation by-products. These results demonstrate that NACA can protect PC12 cells against glutamate cytotoxicity by inhibiting lipid peroxidation, and scavenging ROS, thus preserving intracellular GSH.
\end{abstract}

(C) 2005 Elsevier B.V. All rights reserved.

Theme: Disorders of the nervous system

Topic: Neurotoxicity

Keywords: Oxidative stress; NACA; GSH; Glutamate; Neurodegeneration; PC12 cell

\section{Introduction}

Glutamate, an excitatory amino acid, is one of the major neurotransmitters in the central nervous system (CNS). Elevated levels of extracellular glutamate can acutely damage neurons, have been postulated to mediate CNS damage from conditions such as hyperglycemia, ischemia, hypoxia [8], and may be involved in CNS disorders such as Huntington's, Alzheimer's, and Parkinson's diseases

\footnotetext{
* Corresponding author. Fax: +1 5733416033 .

E-mail address: nercal@umr.edu (N. Ercal).
}

$[19,10]$. Two mechanisms have been proposed for glutamate toxicity. The first mechanism explains the excitotoxicity of glutamate as being mediated through three types of excitatory amino acid receptors [20]. Besides receptormediated glutamate excitotoxicity, it has also been proposed that elevated levels of extracellular glutamate inhibits cystine uptake, which leads to a marked decrease in cellular GSH levels, resulting in the induction of oxidative stress [21].

Cysteine is the critical component for intracellular GSH synthesis. Because of redox instability, almost all of the extracellular cysteine is present primarily in its oxidized state, cystine, which is taken up by cells via a cystine/ glutamate transporter, the $X_{\mathrm{c}}^{-}$system [3]. Studies indicate 
that glutamate and cystine share the same transporter; therefore, elevated levels of extracellular glutamate competitively inhibit cystine transport, which leads to depletion of intracellular GSH [2,3]. Depletion of reduced glutathione results in decreased antioxidant capacity of the cell, accumulation of ROS (reactive oxygen species), and ultimately apoptotic cell death. Several studies have demonstrated the induction of oxidative stress by glutamate in various cell lines including immature cortical neurons [22,29], oligodendroglia [25], cultured rat astrocytes [7], neuroblastoma cells [21], and PC12 cells [13].

In an attempt to protect cells against glutamate toxicity, we investigated the effects of proglutathione agents on the enhancement of intracellular GSH. Supplementing cells with antioxidants such as NAC, lipoic acid (LA) [17], tocopherol [27], and probucol [23] has shown protective effects against glutamate toxicity, mostly by replenishing GSH. However, in certain neurological diseases, such as cerebral ischemia and Parkinson's disease, enhancement of tissue GSH in brain regions may not be attained, because many antioxidant agents cross the blood-brain barrier poorly [26,14].

Recently, an amide of NAC, $N$-acetylcysteine amide (NACA), was synthesized. Because of its neutral carboxyl group (Fig. 1), NACA has the ability of lipophilicity and thereby cell-permeability [1]. NACA crosses the bloodbrain barrier, scavenges free radicals, chelates copper, and attenuates myelin oligodendrocyte glycoprotein (MOG)induced experimental autoimmune encephalomyelitis in a multiple sclerosis mouse model [24]. Further evidence of the efficient membrane permeation of NACA was demonstrated in a recent study [16] which assessed NACA for its antioxidant and protective effects in a model using human red blood cells. The authors also proposed the possible usage of NACA in the treatment of neurodegeneration and other oxidation mediated disorders. Our findings with NACA also convince us that it has the ability to moderately chelate lead and protect against lead-induced oxidative stress (unpublished data).

With this background, we investigated the protective effects of NACA, and attempted to gain insights into the mechanism behind its protection against glutamateinduced cytotoxicity in PC12 cells.

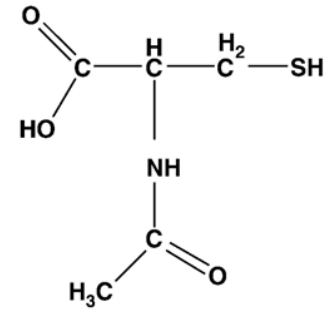

N-Acetylcysteine (NAC)

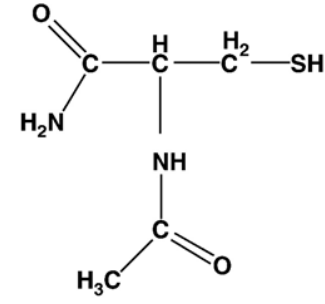

N-Acetylcysteine amide (NACA)
Fig. 1. Structures of NAC and NACA.

\section{Materials and methods}

The $N$-(1-pyrenyl)-maleimide (NPM) was purchased from Aldrich (Milwaukee, WI, USA). N-acetylcysteine amide (NACA) was provided by one of the co-authors, Dr. Glenn Goldstein. High-performance liquid chromatography (HPLC)-grade solvents were purchased from Fisher Scientific (Fair Lawn, NJ). All other chemicals were purchased from Sigma (St. Louis, MO, USA).

\subsection{Cell culture and toxicity studies}

Stock culture of PC12 cells, purchased from ATCC, were grown in $75 \mathrm{~cm}^{2}$ tissue culture flasks in RPMI 1640 , supplemented with $10 \%$ (v/v) heat-inactivated horse serum, and $5 \%(\mathrm{v} / \mathrm{v})$ fetal bovine serum, to which $1 \%(\mathrm{v} / \mathrm{v})$ penicillin and streptomycin were added. Cultures were maintained at $37{ }^{\circ} \mathrm{C}$ in a humidified atmosphere containing $5 \% \mathrm{CO}_{2}$. The cells were passed twice a week. Unless specified, all the experiments were performed using Dulbecco's modified Eagle's medium (DMEM) as differentiation media, supplemented with $0.5 \%(\mathrm{v} / \mathrm{v})$ fetal bovine serum, $1 \%(\mathrm{v} / \mathrm{v})$ penicillin and streptomycin. PC12 cells were plated at a density of $25 \times 10^{3}$ cells/ well in a 24-well collagen-coated plate for morphological assessment. The plate was divided into five groups in triplicate: (1) control: no glutamate, no NACA; (2) Nerve growth factor (NGF) control: NGF (100 ng/ml), no glutamate, no NACA; (3) NACA only: NGF (100 ng/ $\mathrm{ml})$, no glutamate, NACA $(750 \mu \mathrm{M})$; (4) glutamate only: NGF (100 ng/ml), glutamate (10 mM), no NACA; and (5) Glu + NACA: NGF (100 ng/ml), glutamate (10 mM), NACA $(750 \mu \mathrm{M})$. All wells received $100 \mathrm{ng} / \mathrm{ml}$ NGF every other day, except Group I. After 1 week, cells were treated or not (control) with $10 \mathrm{mM}$ glutamate, with or without NACA, for $24 \mathrm{~h}$. Twenty-four hours later, the cells were fixed with $0.5 \%(\mathrm{v} / \mathrm{v})$ glutaraldehyde in PBS and micropictures were taken.

For the lactate dehydrogenase (LDH) assay, cells were plated at a density of $2.5 \times 10^{5}$ cells/well in a 24 -well collagen-coated culture plate and, after $24 \mathrm{~h}$, the medium was replaced with fresh DMEM medium containing the desired concentration of glutamate and NACA. After the desired incubation period, the amount of LDH activity released was determined using the kit. For the MTS assay, cells were plated at a density of $10^{5}$ cells/well in a 24-well collagen-coated plate. At the end of the experiments, cell viability was assayed using the kit.

\subsection{LDH assay}

The LDH activity assay was performed with the CytoTox96 ${ }^{\circledR}$ Non-Radioactive Cytotoxicity Assay kit (Promega, Madison, WI, USA), which quantitatively measured the activity of LDH, a stable cytosolic enzyme that is released upon cell lysis (Technical Bulletin No. 163, 
Promega). LDH in culture supernatants was measured with a 30-min coupled enzymatic assay, which resulted in the conversion of a tetrazolium salt into a red formazan product. The amount of color formed was proportional to the degree of damage to the cell membranes. Absorbance data was collected using a BMG microplate reader (BMG Labtechnologies, Inc., Durham, NC, USA) at $490 \mathrm{~nm}$. LDH leakage was expressed as the percentage (\%) of the maximum LDH release in the cells treated with glutamate alone $(100 \%)$, according to the formula

$\% \mathrm{LDH}$ released $=\frac{\text { Experimental } \mathrm{LDH} \text { release }}{\text { Maximum } \mathrm{LDH} \text { release }} \times 100$

\subsection{MTS assay}

MTS assay (Cell Titer 96 ${ }^{\circledR}$ Aqueous One solution cell proliferation Assay, Promega) is a cell proliferation assay in which the administered [3-(4,5-dimethyl thiazol-2-yl)-5-(3carboxymethoxy phenyl)-2-(4-sulfophenyl)-2 $H$-tetrazolium, inner salt, MTS] [9] is bioreduced by viable cells to a colored formazan product that is soluble in media. Absorbance at $490 \mathrm{~nm}$ is proportional to the number of living cells in the culture.

\subsection{GSH measurement}

Cellular levels of GSH were determined by using the method developed in our laboratory [34]. Cells were seeded at a density of $8 \times 10^{4}$ cells $/ \mathrm{cm}^{2}$ on poly-D-lysine-coated $(0.05 \mathrm{mg} / \mathrm{ml}) 75 \mathrm{~cm}^{2}$ flasks $(5 \mathrm{ml} /$ flask) for GSH measurement. After $24 \mathrm{~h}$, the flasks were incubated with fresh medium containing glutamate $(10 \mathrm{mM})$, or BSO $(0.2 \mathrm{mM})$ or $\mathrm{Glu}+\mathrm{BSO}+$ NACA $(750 \mu \mathrm{M})$ at $37^{\circ} \mathrm{C}$ for another $24 \mathrm{~h}$. After the incubation period, cells were removed from the cultures and homogenized in serine borate buffer $(100 \mathrm{mM}$ Tris-HCl, $10 \mathrm{mM}$ boric acid, $5 \mathrm{mM}$ L-serine, $1 \mathrm{mM}$ DETAPAC, pH 7.4). Twenty (20) $\mu$ l of the diluted cell homogenate was added to $230 \mu \mathrm{l}$ of serine borate buffer and $750 \mu \mathrm{l}$ of NPM ( $1 \mathrm{mM}$ in acetonitrile). The resulting solutions were incubated at room temperature for $5 \mathrm{~min}$. The reaction was stopped by the addition of $5 \mu \mathrm{l}$ of $2 \mathrm{~N} \mathrm{HCl}$. The samples were then filtered through a $0.2-\mu \mathrm{m}$ Acrodisc filter and injected onto the HPLC system.

\subsection{Intracellular ROS measurement}

The cellular ROS accumulation was measured using the 2', 7'-dichlorofluorescin diacetate (DCFH2-DA) method [18]. DCFH2-DA is a nonfluorescent compound, and it can be enzymatically converted to highly fluorescent compound, $\mathrm{DCF}$, in the presence of ROS. After exposure to glutamate, with or without NACA, the cells $\left(10^{6} / \mathrm{ml}\right)$ were incubated in 2 $\mathrm{ml}$ of $140 \mathrm{mM} \mathrm{NaCl}, 5 \mathrm{mM} \mathrm{KCl}, 1 \mathrm{mM} \mathrm{MgCl} 2,5.6 \mathrm{mM}$ glucose, $1.5 \mathrm{mM} \mathrm{CaCl}_{2}$, and $20 \mathrm{mM}$ HEPES-Na, $\mathrm{pH} 7.4$, and allowed to take up $5 \mu \mathrm{M}$ DCFH2-DA at $37{ }^{\circ} \mathrm{C}$ for $20 \mathrm{~min}$, in an atmosphere of $95 \%$ air and $5 \% \mathrm{CO}_{2}$. After loading, DCF fluorescence was measured at $485 \mathrm{~nm}$ excitation and $520 \mathrm{~nm}$ emission.

\subsection{MDA measurement}

To prepare the solution, $350 \mu \mathrm{l}$ of straight cell homogenate, $100 \mu 1$ of $500 \mathrm{ppm}$ BHT (butylated hydroxytoluene), and $550 \mu \mathrm{l}$ of $10 \%$ TCA (trichloroacetic acid) were combined and boiled for $30 \mathrm{~min}$. The tubes were cooled on ice and centrifuged for $10 \mathrm{~min}$ at $2500 \mathrm{rpm}$. Five hundred (500) $\mu \mathrm{l}$ of the supernatant was removed and $500 \mu \mathrm{l}$ of TBA (thiobarbituric acid) was added. The tubes were boiled again for $30 \mathrm{~min}$, and then cooled on ice. From this solution, 500 $\mu 1$ were removed, added to $1.0 \mathrm{ml}$ of $n$-butanol, vortexed, and centrifuged for $5 \mathrm{~min}$ at $60 \times g$ to facilitate a phase separation. The top layer was then filtered through $0.45-\mu \mathrm{m}$ filters and injected onto a $5-\mu \mathrm{m} \mathrm{C}_{18}$ column $(250 \times 4.6 \mathrm{~mm})$ on a reverse phase HPLC system. The mobile phase consisted of $69.4 \% 5 \mathrm{mM}$ sodium phosphate buffer ( $\mathrm{pH} 7.0$ ), 30\% acetonitrile, and $0.6 \%$ THF (tetrahydrofuran). The excitation wave length was $515 \mathrm{~nm}$; the emission wave length was $550 \mathrm{~nm}$ [12].

\subsection{Protein determination and statistical analysis}

Protein levels were determined by the Bradford method with Coomassie Blue (Bio-Rad) [6]. The data were given as the mean $\pm \mathrm{SD}$. The one-way analysis of variance test was used to analyze the significance of the differences between the control and experimental groups.

\section{Results}

\subsection{Protection from glutamate toxicity}

Glutamate toxicity was evaluated by (1) morphological assessment of PC12 cells in the presence of glutamate, (2) measuring the amount of LDH released in the media $24 \mathrm{~h}$ after glutamate exposure, and (3) measuring cell viability using MTS assay. As shown in Fig. 2, cells completely lost the normal morphology of their neurites in the presence of 10 mM glutamate, as compared to the control cells. To determine whether NACA can protect the cells from glutamate toxicity, PC12 cells were exposed to $10 \mathrm{mM}$ glutamate for $24 \mathrm{~h}$ in the presence of $750 \mu \mathrm{M}$ NACA, and cell viability was examined by light microscopy. The addition of NACA protected the PC12 cells from glutamate toxicity by slightly decreasing the bleb formation on neurites.

To quantify the protection provided by NACA, PC12 cells were exposed to $10 \mathrm{mM}$ glutamate in the presence of NACA for $24 \mathrm{~h}$, and then the amount of LDH released was measured using the LDH assay. As shown in Fig. 3, inclusion of $750 \mu \mathrm{M} \mathrm{NACA}$ in the assay completely 


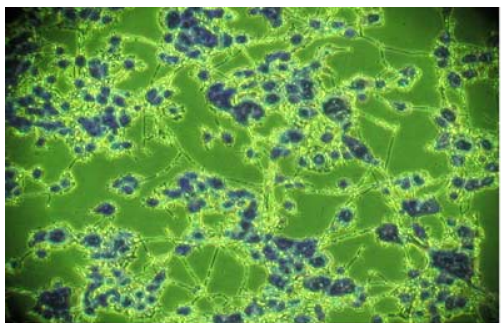

Control

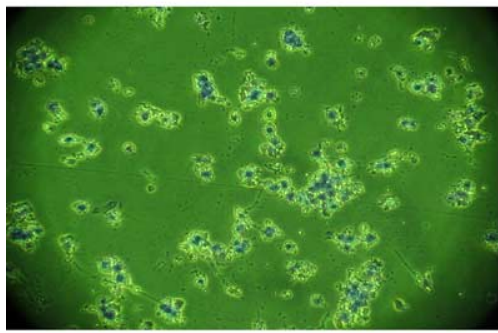

Glutamate only (10 mM)

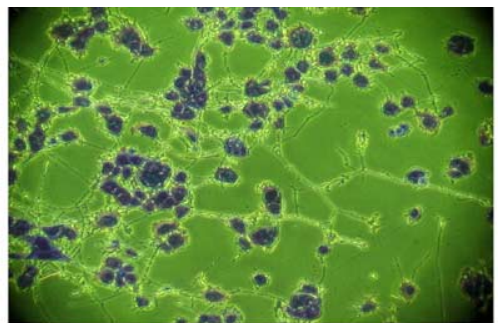

NACA only $(750 \mu \mathrm{M})$

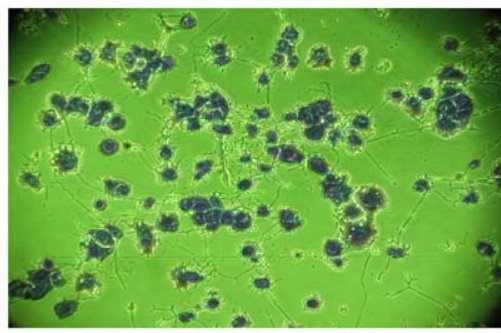

Glutamate $(10 \mathrm{mM})+$ NACA $(750 \mu \mathrm{M})$

Fig. 2. The cytotoxic response of PC12 cells to glutamate and protection by NACA. PC12 cells were plated at a density $25 \times 10^{3}$ cells/well in a $24-w e l l$ plate and grown for $24 \mathrm{~h}$ in culture medium; then, they were treated or not (control) with $10 \mathrm{mM}$ Glu with or without NACA, as described in Materials and methods. Twenty-four hours later, cells were examined and photographed.

protected the cells from cell damage, even in the presence of $10 \mathrm{mM}$ glutamate (the \% LDH released was $28.9 \pm 3.7 \%$ ). Similar results are shown in Fig. 4, where cells were exposed to $10 \mathrm{mM}$ glutamate in the presence of NACA for $24 \mathrm{~h}$, and the cell viability was assessed by the MTS assay.

\subsection{Effect of NACA on GSH levels in PC12 cells}

NACA treatment significantly increased PC12 cell GSH levels. When cells were exposed to $10 \mathrm{mM}$ glutamate, a significant reduction in GSH levels was observed (Table 1). At a $750-\mu \mathrm{M}$ concentration and $24-\mathrm{h}$ treatment time, NACA

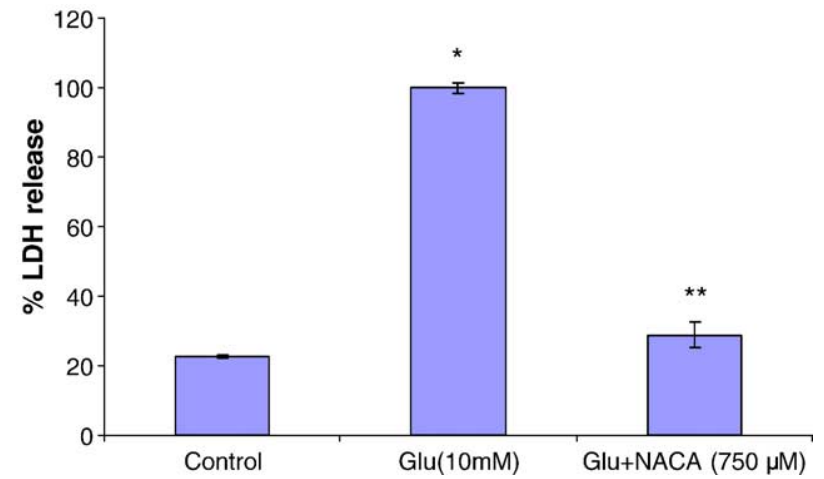

Fig. 3. Protective effect of NACA against glutamate cytotoxicity. Cells were plated and grown for $24 \mathrm{~h}$ in a culture medium; then, they were treated or not (control) with $10 \mathrm{mM}$ Glu, with or without NACA. Twenty-four hours later, the \% LDH release was determined using LDH analysis. Values represent means \pm SD. NACA only group $\% \mathrm{LDH}$ release was similar to the control group. Statistically different values of $* P<0.0005$ were determined, compared to control. ${ }^{*} P<0.0005$ compared to glutamatetreated group. increased the PC12 cell GSH level twofold, compared to the control group. Interestingly, similar results were obtained when Chinese hamster ovary $(\mathrm{CHO})$ cells were incubated with NACA (data not shown).

\subsection{GSH levels in the presence of glutamate and BSO: effect of NACA}

The intracellular levels of GSH were determined in PC12 cells incubated with $10 \mathrm{mM}$ glutamate for $24 \mathrm{~h}$, and the effects of NACA were analyzed. Treatment of cells with NACA prevented the marked decline of cellular GSH levels that normally occurs after glutamate treatment (Table 1).

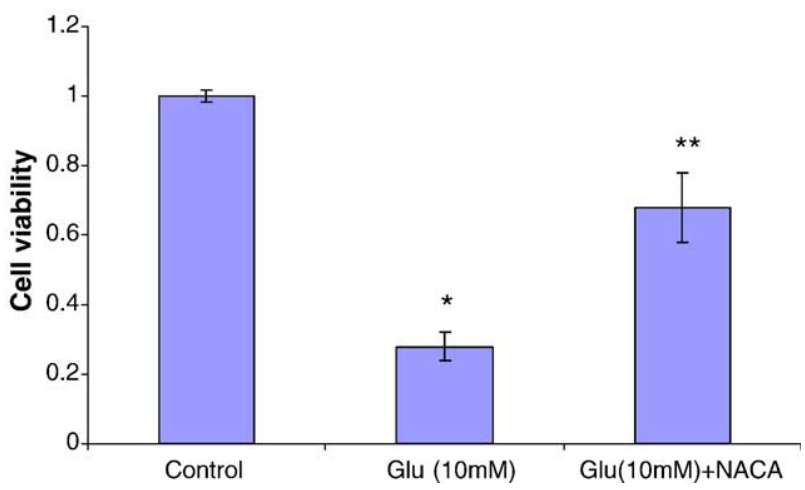

Fig. 4. Effect of NACA on glutamate-induced cytotoxicity. Cells were exposed to $10 \mathrm{mM}$ Glu, with or without NACA, for $24 \mathrm{~h}$; the effects were compared to the control. Cell viability was quantified by the MTS assay. Values represent means \pm SD. NACA only group cell viability was similar to the control group. Statistically different values of $* P<0.05$ were determined, compared to control. $* * P<0.05$ compared to glutamate-treated group. 
Table 1

Effect of NACA on intracellular GSH levels in the presence of BSO and glutamate

\begin{tabular}{ll}
\hline Group & GSH levels (nmol/mg protein) \\
\hline Control & $54 \pm 13.4$ \\
GLU $(10 \mathrm{mM})$ & $23 \pm 4.2^{*}$ \\
BSO $(0.2 \mathrm{mM})$ & $\mathrm{ND}$ \\
NACA $(750 \mu \mathrm{M})$ & $112 \pm 17.8^{*}$ \\
GLU + NACA & $88 \pm 11.0^{* *}$ \\
GLU + BSO + NACA & $30 \pm 4.3^{* * *}$ \\
\hline
\end{tabular}

PC12 cells were seeded and grown for $24 \mathrm{~h}$, then they were treated with either GLU $(10 \mathrm{mM})$, NACA $(750 \mu \mathrm{M}), \mathrm{GLU}(10 \mathrm{mM})+$ NACA $(750 \mu \mathrm{M})$, GLU $(10 \mathrm{mM})+$ BSO $(0.2 \mathrm{mM})+$ NACA $(750 \mu \mathrm{M})$, or BSO $(0.2 \mathrm{mM})$. Twenty hours later, cells were removed and analyzed for GSH levels, as described in the text. Values represent means \pm SD. Statistically different values of $* P<0.05$ were determined, compared to control. $* * P<0.001$ compared to glutamate-treated group. ${ }^{* * *} P<0.05$ compared to glutamatetreated group.

Glutamate inhibits cystine uptake, resulting in the loss of cellular GSH, whereas buthionine-sulfoximine inhibits $\gamma$ GCS activity thereby causing the depletion of intracellular GSH [15]. To determine whether the increase in intracellular GSH by NACA is $\gamma$-GCS-dependent, cells were treated with $0.2 \mathrm{mM}$ BSO. The simultaneous treatment of glutamate and BSO depleted the cell GSH to almost undetectable levels (Table 1). Interestingly, in GSH synthesis-arrested cells, NACA treatment was effective and maintained $56 \%$ of the cells' GSH levels. Supporting these data, increase in cysteine levels by NACA in glutamate-exposed cells was observed (Fig. 5), which explains the ability of NACA to facilitate extracellular supply of cysteine necessary for GSH synthesis.

\subsection{Protection by NACA against glutamate-induced accumulation of ROS and lipid peroxidation}

Glutamate treatment increased DCF fluorescence nearly 2-fold compared with the corresponding control cells.

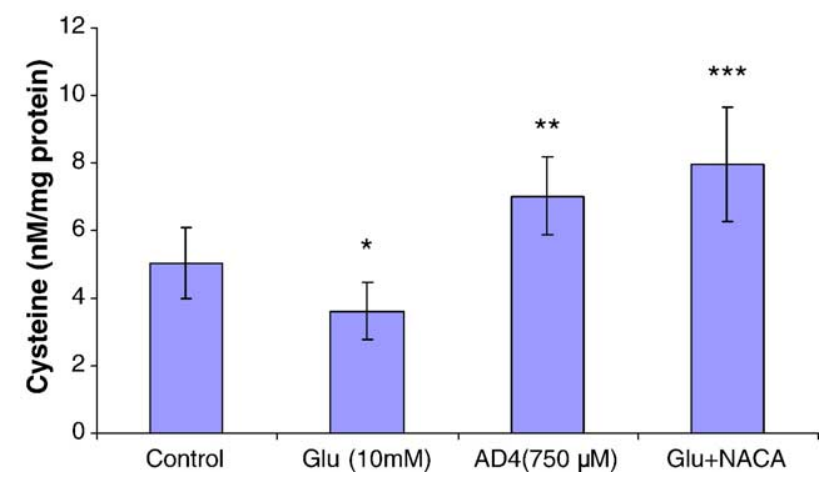

Fig. 5. Effects of NACA on cysteine levels in PC12 cells. Cells were plated and grown for $24 \mathrm{~h}$, then they were exposed to glutamate $(10 \mathrm{mM})$ in the presence or absence of NACA $(750 \mu \mathrm{M})$. Twenty-four hours later, the cells were harvested and cysteine levels were measured. Values represent means \pm SD. Statistically different values of $* P<0.005$ and $* * P<0.05$ were determined, compared to control. ${ }^{* * *} P<0.05$ compared to glutamatetreated group.
NACA protected cells against glutamate cytotoxicity by decreasing the glutamate-induced ROS accumulation (Fig. 6). Malondialdehyde (MDA) is a by-product of a free radical attack on lipids. Marked increase in MDA levels was observed in glutamate-exposed cells, as compared with the corresponding control cells (Table 2). Treatment with NACA completely protected cells against glutamate toxicity by lowering MDA levels.

\section{Discussion}

PC-12, a sympathetic nerve cell line derived from rat pheochromocytoma, has been widely used for neurological studies $[30,13]$. In this study, we determined that a high concentration of glutamate-induced oxidative toxicity was characterized by various potentially detrimental changes in intracellular GSH levels, ROS levels, MDA levels, and LDH activity, resulting in a reduction of PC12 cell viability. Treatment with NACA increased intracellular GSH, and reduced MDA levels, thereby attenuating glutamate-induced cytotoxicity. Evaluation was done by LDH and MTS assay.

Glutamate cytotoxicity has been attributed to either excitatory action through the activation of glutamate receptors [8] or inhibition of cystine uptake that leads to the decreased GSH levels [13,22]. Although PC12 cells express NMDA receptors, toxicity exhibited by glutamate does not solely relate to the presence of these receptors, as NMDA has no effect on PC12 cell death $[30,13]$.

There is a wide body of evidence that disruption of intracellular redox homeostasis by high concentrations of glutamate is a major contributing mechanism of cellular damage in vivo. Under conditions such as cerebral ischemia, extracellular glutamate levels increase $800 \%$; this would lead

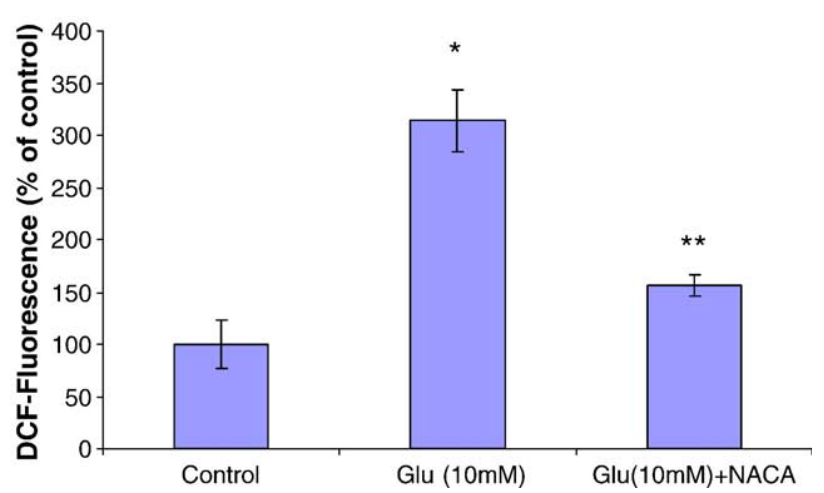

Fig. 6. Effects of NACA on glutamate-induced intracellular accumulation of ROS. Cells were plated and grown for $24 \mathrm{~h}$, then they were exposed to glutamate $(10 \mathrm{mM})$ in the presence or absence of NACA $(750 \mu \mathrm{M})$. Formation of ROS was detected using $\mathrm{DCFH}_{2}$-DA oxidation and fluorescence. The increase in DCF fluorescence was then evaluated as described in Materials and methods. The results were expressed as a relative percent of DCF fluorescence in control cells. Values represent means $\pm \mathrm{SD}$. NACA only group DCF fluorescence was similar to the control group. Statistically different values of $* P<0.01$ were determined, compared to control. ${ }^{*} P<0.05$ compared to glutamate-treated group. 
Table 2

Effects of NACA on MDA levels in glutamate-exposed PC12 cells

\begin{tabular}{lc}
\hline Group & MDA levels (nmol/100 mg protein) \\
\hline Control & $54 \pm 14$ \\
GLU $(10 \mathrm{mM})$ & $247 \pm 26^{*}$ \\
GLU + NACA & $88 \pm 11^{* *}$ \\
\hline
\end{tabular}

Cells were plated and grown for $24 \mathrm{~h}$, then they were exposed to glutamate $(10 \mathrm{mM})$ in the presence or absence of NACA $(750 \mu \mathrm{M})$. Twenty-four hours later, the cells were harvested and malondialdehyde was measured. Values represent means \pm SD. NACA only group MDA levels were similar to the control levels. Statistically different values of $* P<0.005$ were determined, compared to control. ${ }^{* *} P<0.05$ compared to glutamate-treated group.

to a marked decrease in brain GSH levels by blocking cystine uptake $[5,31,28]$. GSH plays an important role in antioxidant defense, and redox regulation. GSH deficiency has been associated with various neurodegenerative diseases [11].

Intracellular GSH levels were determined by the $X_{\mathrm{c}}^{-}$and ASC systems. The $X_{\mathrm{c}}^{-}$system transports cystine intracellularly in exchange for glutamate, whereas the ASC system is a $\mathrm{Na}^{+}$-dependent neutral amino acid transporter that mediates the cellular transport of cysteine [4]. After uptake, cystine is reduced to cysteine for intracellular glutathione synthesis [33]. However, elevated levels of glutamate inhibit cystine uptake and subsequent restriction of cysteine availability for the cell, leading to GSH depletion. In the present study, incubation of PC12 cells with glutamate resulted in reduction of GSH (Table 1) and cysteine levels (Fig. 5) when compared to the control group. Reduced levels of cysteine indicate that the presence of excess glutamate inhibited cystine uptake, which led to decreased GSH levels. NACA treatment was able to increase GSH (Table 1) and cysteine levels (Fig. 5) and effectively reversed the inhibitory action of glutamate. Increases in GSH and cysteine levels were also observed 30 min after NACA was administered to mice (unpublished). The possible mechanism for NACA to facilitate the supply of cysteine may be by readily reaching the cell's interior and becoming deacetylated to form cysteine, as occurs for the parent molecule, $N$-acetylcysteine [32].

In a recent study, it was reported that NACA seemed to act as a sulfhydryl group donor for GSH synthesis in GSH synthesis-arrested cells [24]. To understand whether NACA can restore the GSH levels in GSH synthesis-arrested cells, we incubated PC12 cells with glutamate $(10 \mathrm{mM})$ plus BSO $(0.2 \mathrm{mM})$ in the presence of NACA $(750 \mu \mathrm{M})$. Results showed that NACA elevated intracellular GSH levels in the presence of BSO, suggesting that the effect is $\gamma$-GCSindependent. Therefore, NACA itself may act as a sulfhydryl group donor for GSH synthesis. This was further explained by Leonid Grinberg et al. in their recent study. According to the study, NACA was able to reduce GSSG (glutathione disulfide) to GSH by a nonenzymatic thioldisulfide exchange [16].

Depletion of intracellular GSH may be due to glutamateinduced accumulation of ROS within the cell. ROS levels were measured using peroxide-sensitive dye DCF. A significant increase in ROS accumulation was observed in glutamate-treated cells. In the presence of NACA, the increased ROS accumulation induced by glutamate was significantly reduced (Fig. 6). As reported in earlier studies, glutamate induces lipid peroxidation [17,23] in PC-12 cells. In our study, this was assessed by measuring MDA levels, which were elevated nearly fivefold with glutamate. Concomitant reduction of GSH levels contributed to its fast metabolism as a substrate for glutathione peroxidase in order to eliminate lipid peroxides from glutamate-exposed cells. Unavailability of GSH as a substrate for glutathione peroxidase stalls the process of lipid peroxide decomposition, thus building up the levels of MDA. NACA supplied an adequate amount of GSH as a substrate for glutathione peroxidase, to effectively decompose lipid peroxides in the cells, so that MDA levels were reduced.

In summary, we have shown that NACA protects PC12 cells against glutamate-induced cytotoxicity by preventing glutamate-induced loss of cellular GSH and inhibiting lipid peroxides. We have also demonstrated that restoration of GSH synthesis by NACA in GSH synthesis-arrested cells is $\gamma$-GCS-independent. The possible mechanisms of NACA for enhancement of GSH are (1) supplying the rate-limiting substrate cysteine to the cells and (2) reducing GSSG to GSH by a nonenzymatic thiol-disulfide exchange. NACA has also been reported to cross the blood-brain barrier [24]. Considering the protective effects of NACA against glutamate-induced cytotoxicity, in which oxidative stress seems to be involved, NACA may be helpful in neurodegenerative disorders such as cerebral ischemia [28], and Parkinson's disease [14] where GSH levels are depleted in certain regions of the brain.

\section{Acknowledgments}

The authors like to thank Barbara Harris for carefully editing the manuscript and Dr. Avi Livnat for providing NACA and his help with the discussion. Dr. Ercal was supported by 1 R15 ES012167-01A1 from the NIEHS, NIH.

\section{References}

[1] D. Atlas, E. Melamed, D. Offen, Brain targeted low molecular weight hydrophobic antioxidant compounds, U.S. Patent No. 5,874,468 (1999).

[2] S. Bannai, Transport of cystine and cysteine in mammalian cells, Biochem. Biophys. Acta 779 (3) (1984) 289-306.

[3] S. Bannai, E. Kitamura, Transport interaction of L-cystine and Lglutamate in human diploid fibroblasts in culture, J. Biol. Chem. 255 (6) (1980) 2372-2376.

[4] S. Bannai, N. Tateishi, Role of membrane transport in metabolism and function of glutathione in mammals, J. Membr. Biol. 89 (1) (1986) $1-8$.

[5] H. Benveniste, J. Drejer, A. Schousboe, N.H. Diemer, Elevation of the extracellular concentrations of glutamate and aspartate in rat hippocampus during transient cerebral ischemia monitored by intracerebral microdialysis, J. Neurochem. 43 (5) (1984) 1369-1374. 
[6] M.M. Bradford, A rapid and sensitive method for the quantitation of microgram quantities of protein utilizing the principle of protein-dye binding, Anal. Biochem. 72 (1976) 248-254.

[7] Y. Cho, S. Bannai, Uptake of glutamate and cysteine in C-6 glioma cells and in cultured astrocytes, J. Neurochem. 55 (6) (1990) 2091-2097.

[8] D.W. Choi, Glutamate neurotoxicity and diseases of the nervous system, Neuron 1 (8) (1988) 623-634.

[9] A.H. Cory, T.C. Owen, J.A. Barltrop, J.G. Cory, Use of an aqueous soluble tetrazolium/formazan assay for cell growth assays in culture, Cancer Commun. 3 (7) (1991) 207-212.

[10] J.T. Coyle, P. Puttfarcken, Oxidative stress, glutamate, and neurodegenerative disorders, Science 262 (5134) (1993) 689-695

[11] J. Drake, J. Kanski, S. Varadarajan, M. Tsoras, D.A. Butterfield, Elevation of brain glutathione by gamma-glutamylcysteine ethyl ester protects against peroxynitrite-induced oxidative stress, J. Neurosci. Res. 68 (6) (2002) 776-784.

[12] H.H. Draper, E.J. Squires, H. Mahmoodi, J. Wu, S. Agarwal, M. Hadley, A comparative evaluation of thiobarbituric acid methods for the determination of malondialdehyde in biological materials, Free Radical Biol. Med. 15 (4) (1993) 353-363.

[13] P. Froissard, D. Duval, Cytotoxic effects of glutamic acid on PC12 cells, Neurochem. Int. 24 (5) (1994) 485-493.

[14] M.E. Gotz, A. Freyberger, P. Riederer, Oxidative stress: a role in the pathogenesis of Parkinson's disease, J. Neural Transm., Suppl. 29 (1990) 241-249.

[15] O.W. Griffith, M.E. Anderson, A. Meister, Inhibition of glutathione biosynthesis by prothionine sulfoximine ( $S$ - $n$-propyl homocysteine sulfoximine), a selective inhibitor of gamma-glutamylcysteine synthetase, J. Biol. Chem. 254 (4) (1979) 1205-1210.

[16] L. Grinberg, E. Fibach, J. Amer, D. Atlas, $N$-acetylcysteine amide, a novel cell-permeating thiol, restores cellular glutathione and protects human red blood cells from oxidative stress, Free Radical Biol. Med. 38 (1) (2005) 136-145.

[17] D. Han, C.K. Sen, S. Roy, M.S. Kobayashi, H.J. Tritschler, L. Packer, Protection against glutamate-induced cytotoxicity in C6 glial cells by thiol antioxidants, Am. J. Physiol. 273 (1997) 1771-1778.

[18] W. Hong, J.A. Joseph, Quantifying cellular oxidative stress by dichlorofluorescein assay using microplate reader, Free Radical Biol. Med. 27 (5-6) (1999) 612-616.

[19] B. Meldrum, J. Garthwaite, Excitatory amino acid neurotoxicity and neurodegenerative disease, Trends Pharmacol. Sci. 11 (9) (1990) $379-387$.

[20] D.T. Monaghan, R.J. Bridges, C.W. Cotman, The excitatory amino acid receptors: their classes, pharmacology, and distinct properties in the function of the central nervous system, Annu. Rev. Pharmacol. Toxicol. 29 (1989) 365-402.

[21] T.H. Murphy, M. Miyamoto, A. Sastre, R.L. Schnaar, J.T. Coyle,
Glutamate toxicity in a neuronal cell line involves inhibition of cystine transport leading to oxidative stress, Neuron 2 (6) (1989) $1547-1558$.

[22] T.H. Murphy, R.L. Schnaar, J.T. Coyle, Immature cortical neurons are uniquely sensitive to glutamate toxicity by inhibition of cystine uptake, FASEB J. 4 (6) (1990) 1624-1633.

[23] M. Naito, H. Umegaki, A. Iguchi, Protective effects of probucol against glutamate-induced cytotoxicity in neuronal cell line PC12, Neurosci Lett. 186 (2-3) (1995) 211-213.

[24] D. Offen, Y. Gilgun-Sherki, Y. Barhum, M. Benhar, L. Grinberg, R.E. Reich, D. Melamed, A low molecular weight copper chelator crosses the blood-brain barrier and attenuates experimental autoimmune encephalomyelitis, J. Neurochem. 89 (5) (2004) 1241-1251.

[25] A. Oka, M.J. Belliveau, P.A. Rosenberg, J.J. Volpe, Vulnerability of oligodendroglia to glutamate: pharmacology, mechanisms, and prevention, J. Neurosci. 13 (4) (1993) 1441-1453.

[26] M. Panigrahi, Y. Sadguna, B.R. Shivakumar, S.V. Kolluri, S. Roy, L. Packer, V. Ravindranath, Alpha-Lipoic acid protects against reperfusion injury following cerebral ischemia in rats, Brain Res. 717 (1-2) (1996) $184-188$

[27] C.M. Pereira, C.R. Oliveira, Glutamate toxicity on a PC12 cell line involves glutathione (GSH) depletion and oxidative stress, Free Radical Biol. Med. 23 (4) (1997) 637-647.

[28] S. Rehncrona, J. Folbergrova, D.S. Smith, B.K. Siesjo, Influence of complete and pronounced incomplete cerebral ischemia and subsequent recirculation on cortical concentrations of oxidized and reduced glutathione in the rat, J. Neurochem. 34 (3) (1980) 477-486.

[29] J. Sagara, K. Miura, S. Bannai, Cystine uptake and glutathione level in fetal brain cells in primary culture and in suspension, J. Neurochem. 61 (5) (1993) 1667-1671.

[30] D. Schubert, H. Kimura, P. Maher, Growth factors and vitamin E modify neuronal glutamate toxicity, Proc. Natl. Acad. Sci. U. S. A. 89 (17) (1992) 8264-8267.

[31] B.R. Shiva Kumar, S.V. Kolluri, V. Ravindranath, Glutathione and protein thiol homeostasis in brain during reperfusion after cerebral ischemia, J. Pharmacol. Exp. Ther. 274 (3) (1995) 1167-1173.

[32] K. Sjodin, E. Nilsson, A. Hallberg, A. Tunek, Metabolism of $N$-acetylL-cysteine. Some structural requirements for the deacetylation and consequences for the oral bioavailability, Biochem. Pharmacol. 38 (22) (1989) 3981-3985.

[33] J.S. Stamler, A. Slivka, Biological chemistry of thiols in the vasculature and in vascular-related disease, Nutr. Rev. 54 (1996) $1-30$.

[34] R.A. Winters, J. Zukowski, N. Ercal, R.H. Matthews, D.R. Spitz, Analysis of glutathione, glutathione disulfide, cysteine, homocysteine, and other biological thiols by high-performance liquid chromatography following derivatization by $n$-(1-pyrenyl)maleimide, Anal. Biochem. 227 (1) (1995) 14-21. 